\title{
EDUCAÇÃO ORIENTADA PARA O EMPREENDEDORISMO E A FORMAÇÃO DE COMPORTAMENTOS FINANCEIROS: Uma reflexão a partir dos protagonistas envolvidos
}

Antonia Márcia Sousa ${ }^{1}$

Ruan Carlos Dos Santos ${ }^{2}$

Alexandre Oliveira Lima ${ }^{3}$

Rogeane Morais Ribeiro ${ }^{4}$

\footnotetext{
${ }^{1}$ Universidade Federal do Ceara

${ }^{2}$ Universidade do Vale do Itajaí

${ }^{3}$ Universidade da Integração Internacional da Lusofonia Afro-Brasileira

${ }^{4}$ FACULDADE LUCIANO FEIJAO
} 


\title{
EDUCAÇÃO ORIENTADA PARA O EMPREENDEDORISMO E A FORMAÇÃO \\ DE COMPORTAMENTOS FINANCEIROS: Uma reflexão a partir dos protagonistas \\ envolvidos
}

\begin{abstract}
Resumo
Este estudo apresenta as contribuições e os direcionamentos de um projeto de educação orientado para o empreendedorismo e a formação de pensamentos que norteiam as finanças comportamentais de estudantes universitários. Metodologicamente traz uma abordagem qualitativa, com fim exploratório e documental. O lócus do estudo é uma Instituição de Ensino Superior no Ceará. Participou da pesquisa alunos e professores envolvidos no projeto denominado Feirão do Imposto, realizado há oito anos na instituição. A coleta ocorreu através de observação participante, relato de experiências e documentos institucionais. Os dados foram analisados a partir de uma adequação da técnica de análise de conteúdo. Achados do estudo apontaram uma disposição dos estudantes em relação aos aspectos de formação para empreender, mas não demonstraram influências diretamente na formação dos seus comportamentos financeiros.
\end{abstract}

Palavras-chave: Educação, Empreendedorismo, Tributos, Comportamentos financeiros.

\section{Introdução}

É mundialmente crescente o desenvolvimento de pesquisas que buscam entender o fenômeno do empreendedorismo e suas distintas correntes de estudos, bem como seus desdobramentos que têm contribuído para a formação da educação para empreender com a ampliação de práticas que envolvem capacidades para identificar e explorar oportunidades que rompem com a inércia gerando inovação e assunção de riscos para empreendedores e consequentemente para o mercado.

Entende-se que as oportunidades são identificadas a partir de distintos fatores advindos das conotações sociais, econômicas, tecnológicas e de outros aspectos que permeiam o ambiente, sendo que no âmbito da educação empreendedora cabe aos educadores o papel de estimular o raciocínio e as competências empreendedoras dos alunos por meio de atividades práticas (Neck, \& Grenne, 2011; Neck, Greene, \& Brush, 2014; Neck, Neck, \& Murray, 2018).

A implantação de ações de cunho ao incentivo a formação de empreendedores, independente da vertente, sinalizam a necessidade de criação de um ambiente prospecto para o empreendedorismo ao demonstrar a importância da construção de técnicas e habilidades que estimulem o pensamento do indivíduo para uma ação empreendedora continua.

Schaefer, \& Minello, (2016) advogam que no Brasil existe um celeiro de necessidade e oportunidade que potencializam a educação empreendedora. Surgindo então a necessidade de se repensar o paradigma educacional a partir da educação básica ao ensino superior com o de técnicas e metodologias que fortaleçam a aprendizagem para o ensino (Mancebo, Silvia, \& Mariano, 2016; Krakauer, Santos, \& Almeida, 2017). 
Entretanto, para que ocorra esse efetivo processo de formação é necessário um ajuste no papel das IES que devem permear pela formação do corpo docente (Rocha, \& Freitas, 2014), cultura empreendedora das Universidades (Matias, Colares, Rocha, \& Carvalho Junior, 2013) em consonância com pensamento e a participação continua e integrada dos alunos (Neck, Neck, \& Murray, 2018).

São estas e outras dimensões, que modificam a conjuntura da formação para empreender de muitos jovens que ingressam na universidade com perspectivas incertas em relação à construção da carreira. Nesse limiar, (Libâneo, 2013) defende que o papel da educação no contexto coletivo deve aprovisionar saberes que tornem o indivíduo capaz de intervir perante os cenários de incertezas nas esferas econômicas, políticas e sociais.

Nessa ótica, ao sair do cenário macro da educação e voltar-se para a educação empreendedora como um método e não como parte do processo (Sarasvathy, 2008; Lima, Lopes, Nassif, \& Silva, 2011; Nassif, Amaral, \& Prando, 2012; Lima, Lopes, Nassif, \& Silva ,2015; Mancebo, Silvia, \& Mariano, 2016), imprimem a urgência de criação de mecanismos educacionais que oportunizem o desenvolvimento de competências empreendedoras na formação desses jovens

Tais afirmações retomam as observações de (Vanevenhoven, 2013) sobre a necessidade de avanços no ensino do empreendedorismo minimizando o uso de metodologias econométricas, que segundo o autor, cria um distanciamento entre os pesquisadores e os reais comportamentos que formam a educação para o empreendedorismo.

Tomando como base os avanços no desenvolvimento e implantação de metodologias para a formação da educação empreendedora de jovens no contexto universitário. Este estudo apresenta um projeto que vem sendo implantado há oito anos em uma instituição de ensino superior no Ceará, denominada de "Feirão do Imposto" que propõe a exposição de elementos balizadores para uma aprendizagem voltada a educação empreendedora e sequencialmente a formação do pensamento para as finanças pessoais dos estudantes a partir da interdisciplinaridade de conhecimentos abordados nas disciplinas de contabilidade, gestão de custos, economia, economia brasileira, matemática, estatística, matemática financeira e gestão financeira.

Partindo do pressuposto que o surgimento das Finanças Comportamentais é uma ramificação inovadora da teoria das finanças que de forma interdisciplinar associou-se aos conceitos de outras áreas como a psicologia, economia, finanças e a sociologia. E de forma complementar mostra a proeminência de elementos que expliquem as motivações que levam o indivíduo a tomar suas decisões financeiras ancorados pelo envolvimento de riscos, incertezas psicológicas e sociais que estão vinculadas diretamente ao comportamento humano e fundamentados na educação para empreender (MCclelland, 1984; Krakauer, 2011; Gomes, Lima, \& Cappelle, 2013). Optou-se por associar esses dois construtos visando compreender a existência de aspectos balizadores para o fomento ao empreendedorismo e a identificação de elementos que envolvem diretamente o cotidiano das finanças comportamentais do indivíduo que de forma implícita comprometem suas interações entre os pares.

No sentido do indivíduo como empreendedor (Drucker, 2005; McClelland, 1961, Shumpeter, 1982) existe uma série de associações influenciadas por contextos decorrentes das condições psicológicas e sociológicas que o habilitam ao enfrentamento de crises provocadas por elementos intrínsecos e extrínsecos ao ambiente.

Ao integrar esse contexto com as finanças comportamentais, advoga-se que os agentes econômicos guiam os indivíduos a uma inclinação de comportamentos que em muitas 
ocasiões desviam de uma decisão pautada diretamente na racionalidade, o que permite explicar muito das emoções, o humor e os erros cognitivos que o influenciam de forma contextual em suas tomadas de decisões (Mosca, 2009).

No horizonte da formação para a educação empreendedora, as finanças comportamentais seguem a defesa de que a racionalidade não é ilimitada, e que as decisões tomadas levam em conta outros fatores que não estão estritamente econômico, comungando com a ideia de (McClelland,1984) ao defender que dentre as possibilidades comportamentais para empreender está o desejo, como força indutora controlada pela razão.

Para (Eatwell, Milgate, \& Neumann, 1987) o comportamento racional individual é norteado por dois fatores, um relacionado sob a certeza e outro sob a incerteza. Quando associado ao indivíduo empreendedor, um está relacionado sob a escolha da certeza que está integrada ao empreender por oportunidade e o outro, escolha sob a incerteza, que tem vínculos diretos com o empreender por necessidade.

Esses direcionamentos aquecem o comportamento do empreendedor nas decisões das finanças comportamentais, levando a um ponto de partida para este estudo que é saber: quais as contribuições e os direcionamentos de um projeto de educação orientado para o empreendedorismo e a formação de comportamentos financeiros em estudantes universitários?

A simbiose desses dois construtos se justifica, ao proporcionar um entendimento em relação aos comportamentos psicológicos, sociais e financeiros do indivíduo. E por apresentar um conhecimento interdisciplinar com a atração de outros fenômenos comportamentais identificados em outros estudos (Shefrin, 2000; Nofsinger, 2001; Asandimitra, \& Kautsar, 2017; Wiryaningtyas \& Pramesthi, 2018).

Nessa ótica o objetivo desse estudo é apresentar as contribuições e os direcionamentos de um projeto de educação orientado para o empreendedorismo e a formação de pensamentos que norteiam as finanças comportamentais de estudantes universitários. Este estudo está fundamentado em três seções, inicialmente apresenta-se a introdução com seus aspectos estratégicos, em seguida destacam-se os construtos educação empreendedora e finanças comportamentais que sustentam a literatura. Logo a seguir apresenta-se o delineamento metodológico, a experiência da prática em educação empreendedora nas finanças comportamentais, analise dos resultados, considerações finais com suas limitações, propostas de estudos futuros e as referências bibliográficas.

\section{Educação Empreendedora}

Um campo teórico que ainda demanda de encadeamento de discussões mas que paulatinamente apresenta um crescimento nas questões que permeiam a formação e o desenvolvimento de novas metodologias no âmbito das escolas de todos os níveis no Brasil.

Estudos têm mostrado que a educação empreendedora tem sido uma mola propulsora para o desenvolvimento de uma nação (Vanevenhoven, 2013; UNCTAD, 2015; GEM, 2018), que cotidianamente aperfeiçoa competências possibilitando uma dinâmica na geração e exploração de novas oportunidades de negócios ( Lima, Lopes, Nassif, \& Silva, 2015) que surgem inicialmente com a união de recursos que determinam sua formatação oportunizando o alcance de resultados promissores e aproveitamento de recompensas (Baron, \& Shane, 2007).

A evolução das conferências promovidas pelo órgão internacional da Organização das Nações Unidas - ONU responsável pela economia e pelo desenvolvimento aponta quatro 
áreas-chave para a educação empreendedora: a) incorporação do empreendedorismo na educação e treinamento, b) o desenvolvimento curricular, c) o desenvolvimento do professor e d) o engajamento com o setor privado (UNCTAD, 2011).

Em concomitância, (Schaefer, \& Minello, 2016), enfatizam a relevância de desenvolver e implementar programas de educação empreendedora baseada nas recomendações da Unesco para a educação do século XXI, que são aprender a conhecer, aprender a fazer, aprender a conviver e aprender a ser. Nessa ótica, a educação de cunho teórica bancária abre caminho para a educação empreendedora que, de acordo com (Solomon, Duffy, \& Tarabishy, 2002) o seu objetivo fulcral deve ser divergente do modelo tradicional de educação em negócios, tendo em vista que criar um empreendimento é substancialmente distinto do uso contínuo de ferramentas gerenciais. É possível compreender, que a visão de educação empreendedora, para esses autores, está pautada em aspectos voltados para a liderança, negociação, desenvolvimento de novos produtos, pensamento criativo e exposição à inovação tecnológica.

Portanto, uma instituição de ensino para ser caracterizada como uma instituição empreendedora deve apresentar em seu cotidiano comportamentos proativos, inovadores e tecnológicos que fortaleçam a formação de empreendedores. Em sincronismo com o ambiente externo deve incentivar a educação empreendedora com ações extracurriculares e fora da ambiência universitária, como sugere (Schaefer, \& Minello,2016) ao orientar o uso e incentivo ininterrupto de espaços como: incubadoras de empresas, parque tecnológicos, empresas juniores, células empreendedoras, clubes de empreendedorismo e centros de empreendedorismo, e outros eventos com o intuito de desenvolver o empreendedorismo e competições internas e externas de planos de negócios e práticas empreendedoras, parceiras de ensino com empreendedores, como os arranjos produtivos, cooperativas, pequenas associações de produtores e organizações do terceiro setor, transferências de tecnologia para as empresas, fundos disponíveis para pesquisas e programas de mentores.

Porém, imbricados a estas práticas,, o empreendedor necessita da integração de conhecimentos, no caso específico desse estudo, optou-se por fazer uma associação conteudistas das disciplinas com abordagens financeiras buscando entender como o projeto Feirão do Imposto contribui para a formação de comportamentos financeiros, ao partir do pressuposto que a educação empreendedora vem sendo trabalhada com o uso de distintos métodos. O campo de Finanças para empreendedores é tido como uma área de intersecção entre Finanças Corporativas e Empreendedorismo e tem evoluído como um campo de estudo em ascensão, haja vista que é considerado como um dos pilares mais importantes para o estabelecimento de negócios sustentáveis e perenes (Chemmanur, \& Fulghieri, 2014). Rogers, (2011) afirma que Finanças foram apontadas por empreendedores como sendo a área funcional em que eles têm menos competência, mas a que dedicavam maior parcela do tempo.

De acordo com o Global Financial Development Report (Banco Mundial, 2014) mercados emergentes enfrentam restrições financeiras significativas que minam a contribuição ao emprego, produtividade, crescimento e inovação e associam esse panorama à baixa efetividade na educação em Finanças.

Brito (2016) constatou que de uma relação de 16 fatores, grande parte dos itens classificados no grupo de maior importância estavam circunscritos no campo de finanças, em linha com estudos anteriores (Unger, Rauch, Frese, \& Rosenbusch, 2011) e ratificando a relevância do tema para o contexto empreendedor. 
William, Casey, \& John, (2012) observaram que empreendedores nascentes que detinham um maior nível de conhecimento em finanças estavam mais suscetíveis ao uso de financiamento externo e, de acordo com o mesmo estudo, as empresas que contavam com financiamento via capital de terceiros mais elevado, apresentaram maiores níveis de receita e taxa de crescimento e sobrevivência superiores, indicando que o arcabouço em Finanças eleva as chances de melhores decisões de financiamento.

Para (Yamamoto, 2018), embora ainda se apresente como um campo fértil, os poucos estudos ratificam a importância do ensino de finanças ao associarem resultados positivos dos negócios com o nível de conhecimento sobre a matéria. Desta forma, verifica-se a necessidade e importância da educação e das finanças voltadas ao empreendedorismo para a sustentabilidade das empresas, qualquer que seja seu porte.

\section{Finanças Comportamentais}

Finanças Comportamentais constitui-se em um novo campo de estudo que refuta os paradigmas da teoria tradicional de finanças, ao afirmar por meio de pesquisas experimentais desenvolvidas inicialmente pelos estudiosos israelenses (Kahneman, \& Tversky,1986), que os investidores não são plenamente racionais e que os mesmos possuem tendências a cometerem erros sistemáticos no processo de tomada de decisão financeira.

O surgimento das Finanças Comportamentais traz consigo uma possibilidade de aperfeiçoamento para o Modelo Moderno de Finanças para os empreendedores, visto que agrega ao mesmo os resultados de pesquisas sobre o comportamento e a irracionalidade do homem; agora percebido como um indivíduo em que as ações e decisões sofrem a influência de emoções e erros cognitivos, fazendo com ele entenda uma situação de diferentes formas em função do modo como analisa a problemática (Halfed, \& Torres, 2001).

Por isso, as finanças comportamentais: a psicologia cognitiva e os limites da arbitragem (Ritter, 2002). A psicologia cognitiva é o estudo científico da cognição dos seres humanos ou dos processos mentais considerados para formar o comportamento humano. Explica os erros sistemáticos cometidos pelos investidores na maneira como tomam decisões em processo de decisão de investimento. As perspectivas sobre os limites da arbitragem prevêem a eficácia das forças de arbitragem sob quaisquer circunstâncias. As finanças comportamentais sugerem que existem "limites à arbitragem", pois existe um comportamento do investidor de comprar o superfaturado e vender os papéis, por sua vez, perturbando a condição de paridade no curto prazo devido à percepção de risco (Ross, Westerfield, Jaffe, \& Jordan, 2008).

As Finanças para empreendedores são tidas como uma área de intersecção entre Finanças Corporativas, comportamentais e Empreendedorismo e tem evoluído como um campo de estudo em ascensão, haja vista que é considerado como um dos pilares mais importantes para o estabelecimento de negócios sustentáveis (Chemmanur, \& Fulghieri, 2014). Isto é ratificado por outros estudos e autores ao afirmarem que a ausência de uma adequada educação financeira pode refletir no insucesso dos empreendimentos (Verdinelli, Lizote, Nascimento, \& Ramezanali, 2015). Ademais, pesquisas mostram que Finanças foi apontada por empreendedores como sendo a área funcional em que eles têm menos competência (Rogers, 2011).

As Finanças Comportamentais buscam explicar os padrões de raciocínio dos investidores, abrangendo os processos emocionais envolvidos e o grau em que interferem no 
processo de tomada de decisão. De acordo com (Ricciardi, \& Simon,2000), as Finanças Comportamentais estuda os fatores psicológicos e sociológicos que influenciam a tomada de decisões financeiras no processo de indivíduos, grupos e entidades. A finança tradicional explica que a racionalidade do investidor e a tomada de decisão se baseiam na hipótese da utilidade esperada (Neumann, \& Morgenstern, 1944), onde, como nas finanças modernas, o conceito subjacente era maximizar a utilidade da riqueza baseada na eficiência informal do mercado.

Além disso, as teorias tradicionais parecem não conseguir explicar determinados fenômenos regularmente observáveis no mercado que as contrariam, as anomalias, de forma que (Yoshinaga, Oliveira, Silveira, \& Barros, 2008) concluem que "evidências empíricas baseadas em dados financeiros indicam que novas teorias são necessárias para que se possa compreender melhor uma gama de importantes fenômenos na área de Finanças", mostrando a relevância da área de Finanças Comportamentais; além disso, afirmam que os aspectos comportamentais sugerem que abordagens que relaxam os pressupostos tradicionais de racionalidade perfeita dos agentes podem gerar bons frutos, justificando o esforço recente de desenvolvimento do campo das Finanças Comportamentais

As finanças comportamentais é uma das áreas de pesquisa mais promissoras da Teoria de Finanças (Yoshinaga, Oliveira, Silveira, \& Barros, 2008). Ainda de acordo com os autores pode-se inferir a existência de um longo caminho a ser trilhado no esforço de incorporação de padrões de cognição mais realistas às teorias desta área do conhecimento.

No sentido geral, as finanças comportamentais, são divididas em macro finanças comportamentais e finanças micro-comportamentais (Pompian, 2006) Macro finanças comportamentais e anomalias de teste da hipótese do mercado eficiente Isso pode ser explicado por modelos de comportamento de pessoas. Subrahmanyam,2007), como (Tseng, 2006), oferece combinar as tradicionais teorias financeiras que sustentam a racionalidade com a teoria de finanças comportamentais, que prevê que o comportamento dos investidores nem sempre é Linha com os critérios de racionalidade, conforme conclui (Subrahmanyam,2007) que as bandeiras financeiras são corretamente entre o comportamento do empreendedor e suas finanças.

Por isso, o comportamento financeiro do empreendedor e sua educação é um esforço consciente dos indivíduos para aumentar o conhecimento sobre empreendedorismo (Gerba, 2012), porque a educação empreendedora não é marketing ou vendas que educam alguém para ser um comerciante, mas tem um significado mais amplo do que apenas ser um vendedor (Nurseto, 2010). Enfim, a educação empreendedora é um olhar para as oportunidades e riscos que o mundo dos negócios enfrenta, ou seja, a perspectiva da educação ensina e estudam os valores, habilidades e comportamentos diante dos desafios da vida para buscar oportunidades com uma ampla gama de riscos que podem ser encontrado (Kurniawan, 2013).

\section{Projeto de Educação para empreender e finanças comportamentais - Feirão do Imposto}

O projeto Feirão do Imposto operacionalizado na perspectiva prática da educação para o empreendedorismo e do estímulo a comportamentos financeiros, ocorre desde 2010, tendo como participantes os alunos do Curso de Administração de uma Instituição de Ensino Superior que atua há mais de 10 anos no Ceará, especificamente na cidade de Sobral.

Ao longo dos anos, o projeto tornou-se parte estratégica do curso, figurando entre os eventos de natureza institucional inserido no calendário acadêmico, passando a ser uma 
atividade obrigatória extracurricular do curso. O número de alunos envolvidos anualmente varia de 150 a 180 participantes, representando aproximadamente 22 alunos por turmas.

A ideação de ajuste aos processos de formação para a educação empreendedora dos alunos deu-se por meio da agregação de elementos metodológicos que apontam o aluno como protagonista do seu conhecimento nos aspectos relacionados a criação e aproveitamento da rede de relações, proatividade, liderança e inovação, que associados aos conteúdos das disciplinas de Economia, Economia Brasileira, Matemática, Contabilidade, Estatística, Matemática Financeira, Contabilidade e Custos, Gestão Financeira e Orçamentária desenvolvem as competências dos alunos em relação a vivência para empreender numa perspectiva de formação que conduza a geração de comportamentos pessoais financeiramente saudáveis, tanto no horizonte pessoal e na criação e sustentabilidade de negócios futuros.

Para (Lima, Lopes, Nassif, \& Silva, 2015) a educação empreendedora de qualidade trabalha com riscos, busca de aperfeiçoamento de competência e explora oportunidade. E ainda segundo os autores, o uso de estratégias pedagógicas estimula o desenvolvimento de capacidades, competências e autoconhecimento, oportunizando o fazer e a vivência empreendedora.

No quesito da relevância dos conhecimentos que permeiam as finanças, (Yamamoto, 2018), defende a necessidade e importância da educação e das finanças voltadas ao empreendedorismo para a sustentabilidade das empresas, qualquer que seja seu porte.

Partindo dessas orientações teóricas, o projeto foi sendo desenhado ao longo desse período longitudinal de oito anos com a seguinte metodologia: Inicialmente, os docentes responsáveis pelo planejamento e orientação definem estudos baseados em temas tributários em evidência no país que diretamente englobam o cenário das empresas e Microempreendedores individuais. Na sequência é formado o grupo composto por uma variação de 5 a 8 participantes, onde é eleito um líder para cada equipe. Após esse fechamento os discentes em acordo com os docentes elencam os produtos ou serviços que se adéquam ao tema abordado, sem seguida ocorre uma reunião de fechamento onde é apresentado um layout para organização do espaço e o cronograma do evento que acontece no segundo semestre de cada ano..

Ao longo dos anos os processos foram sendo adaptados para discussões de questões relacionadas ao cenário econômico vigente. Assim, de forma cronológica iniciado em 2010, a abordagem seminal trouxe o tema "Saiba o que está pagando", contando como atividade prática das disciplinas de Contabilidade e Contabilidade e Custos, envolvendo apenas os alunos dessas duas disciplinas e dos professores das disciplinas de Contabilidade e Matemática para auxiliar nos cálculos dos impostos que seriam apresentados no dia da exposição. Como forma de envolver a comunidade externa, a exposição acontece no horário de 18 as 22 horas, na Boulevard do Arco, um dos pontos turísticos da cidade de Sobral.

Em 2011, o tema trouxe a discussão sobre como "Proporcionar a sociedade o conhecimento sobre o valor dos impostos pagos em produtos". Com o objetivo de conscientizar a população sobralense e das cidades circunvizinhas acerca dos muitos impostos que pagamos no dia a dia. Participaram do evento os alunos das disciplinas de Contabilidade, Contabilidade e Custos, e matemática, se organizando em seis stands com a apresentação de uma diversificação de produtos no horário de 18 as 22 horas, na Boulevard do Arco.

Em 2012, a abordagem temática foi "Conscientização do valor dos impostos cobrado em produtos consumidos". Nessa edição foram expostos produtos variados e 
envolveram discentes das disciplinas de Contabilidade. Contabilidade e Custos e Matemática organizando-se em seis stands na Boulevard do Arco.

Em 2013, o tema para discussão foi o "Ativo invisível no bolso consumidor" objetivando apresentar a sociedade o percentual que fica para o fisco desde a compra de pequenos produtos.

Em 2014, discutiu-se sobre o tema "Meu salário, meus impostos", com o objetivo de levar os alunos e a comunidade a refletir sobre suas finanças comportamentais e os impactos que os tributos causam no cotidiano do alcance dos objetivos individuais e coletivos. Participaram da organização os alunos das disciplinas de Matemática e Contabilidade; Matemática Financeira; Estatística; Contabilidade e Custos; Gestão Financeira e Orçamentária, formando um total de dez stands na Boulevard do Arco. .

Em 2015, a temática "Compromisso coletivo a ser divulgado", envolveu a população e os estudantes das disciplinas de Economia, Economia Brasileira, Matemática e Contabilidade, Matemática Financeira, Estatística, Contabilidade e Custos, Gestão Financeira e Orçamentária..A fundamentação prática foi apresentar em números a arrecadação e aplicação nos serviços públicos.Em 2015 o evento aconteceu em dois momentos, tendo sua abertura com uma palestra sobre "Crise e suas consequências" e no segundo momento a realização de exposição e explanações dos tributos referentes aos produtos foi realizada na Boulevard do Arco.

Em 2016 a temática abordada foi a "Carga tributária: Uma via de duplicação incerta", objetivando informar e conscientizar a população sobre a carga tributária dos mais diversos produtos que consumimos seja nos aspectos domésticos ou sociais, como também informar a população dos impostos arrecadados no âmbito municipal, estadual e federal, sendo exposto em tempo real um telão com o impostômetro. Nessa edição, os docentes e discentes, das disciplinas de Economia, Economia Brasileira, Matemática, Contabilidade, Estatística, Matemática Financeira, Contabilidade e Custos, Gestão Financeira e Orçamentária organizaram o evento em dois momentos: sendo o primeiro com abertura em forma de palestra abordando o assunto sobre "Carga tributária: uma via de duplicação incerta"; e o segundo momento com exposição dos produtos diversificados, na Boulevard do Arco, divididos em 10 stands com suas respectivas cargas tributários, onde nessa edição vários produtos foram comercializados sem a carga tributária.

Em 2017, a temática “ Tributação Brasileira” com a participação dos discentes e docentes das disciplinas de Economia, Economia Brasileira, Matemática, Contabilidade, Matemática Financeira,Estatística, Contabilidade e Custos, Gestão Financeira e Orçamentária, entenderam que a modalidade do feirão sendo realizada com palestra na abertura estava apresentando um maior envolvimento da classe acadêmica. Nesse sentido realizaram a edição de 2017 com foco em disseminar informação sobre o valor pago na tributação de produtos de forma simplificada à população, tendo como palestra de abertura "Tributação Brasileira: Um investimento sem retorno visível". Seguidamente foi realizado na Praça do Teatro São João, a exposição e venda de diversos produtos, divididos em 10 stands com suas respectivas cargas tributárias e a comercialização sem impostos embutidos.

Em 2018, o Feirão do Imposto apresentou uma nova proposta, onde buscou englobar os alunos dos oito semestres do Curso de Administração, orientados pelos professores das disciplinas de Economia, Economia Brasileira, Matemática, Contabilidade, Matemática Financeira, Contabilidade e Custos, Estatística e Gestão Financeira e Orçamentária. O evento teve denominação de I Fórum Regional de Gestão de Tributos com a palestra "Função Social 
dos Tributos", e contou com a participação de trinta empresas, em diversos segmentos, de Sobral e cidades circunvizinhas envolvidas em proporcionar o "O Dia sem Imposto" a população.

A associação das temáticas envolvendo a interdisciplinarização de conhecimentos que culminam em ações práticas de educação para empreender torna-se evidentes a partir da sistematização da formação de redes relacionamentos, iniciativa, assunção ao risco, criatividade, liderança e outras características preponderantes para a efetivação da participação ativa no projeto.

No que concerne ao objetivo da ação, o projeto trata de práticas visíveis voltadas para a educação empreendedora alinhada a finanças, onde se observa que a educação empreendedora cresce em todo o mundo acadêmico através de uma variedade de práticas pedagógicas, e assim, torna-se evidente o fomento do empreendedorismo atrelado a educação (Neck, \& Grenne, 2011; Krakauer, 2014). Por outra vertente verifica-se a o cruzamento entre empreendedorismo e finanças, sejam corporativas ou comportamentais, onde tem se mostrado como um campo crescente e um dos sustentáculos para a continuidade da empresa (Chemmanur, \& Fulghieri, 2014).

Mwasalwiba (2010) ressalta que o estudo e aplicação de finanças empreendedoras é uma tendência relevante e atual em pesquisas e práticas acadêmicas, pois o desenvolvimento de ações ou atividades empreendedoras está relacionado com o acesso às fontes de financiamento e consequentemente a tomada de decisões mediante ao mercado tão turbulento (Mosca, 2009; Khan, Mohammad, \& Nur Alam, 2010). Assim, empreender é um atributo relevante para o profissional do futuro (Hill, Conger, \& Reader, 2010; Vanevenhoven, 2013; UNCTAD, 2015; GEM, 2018), já a educação empreendedora está no meio dos cursos de gestão e de escolas que ofertam disciplinas ligadas a gestão na intenção de transformar o pensar dos discentes, mas ainda está em um processo de construção, buscando novas abordagens pedagógicas em meio a tecnologia, ou seja, está em um processo cíclico, multidisciplinar e contínuo (Hannon, 2006; Neck, \& Greene, 2011).

\section{Aspectos Metodológicos}

As orientações metodológicas desse estudo seguem as ideias de (Minayo, 2012) sobre a abordagem qualitativa ao defender a existência de uma realidade no âmbito das Ciências Sociais que não deve apresentar nenhum nível de quantificação, condição salutar na proposta dessa pesquisa é apresentar as contribuições e os direcionamentos de um projeto de educação empreendedora na formação de pensamentos que norteiam as finanças comportamentais de estudantes universitários. O que nos possibilitou identificar um universo de significados, aspirações, crenças, valores e atitudes (Minayo, 2012) no decorrer das ações implementadas pelos alunos sob a orientação dos professores.

Em relação aos fins insere-se numa proposta exploratória e documental. No cunho exploratório possibilita a apresentação de um nível com alta tendência de interação dos dois fenômenos ainda pouco explorada, entretanto pode ser explicado pela contextualização das teorias e análise dos cenários em ângulos distintos (De Sordi, 2016).

No quesito documental apropriou-se das orientações de (Patton,2002) ao utilizar documentos sem tratamento analítico como relatório, comunicação interna, fotos, dentre outros elementos fornecidos pela Instituição de Ensino Superior pesquisada. 
O lócus do estudo é o Curso de Administração de uma Instituição de Ensino Superior privada que atua há mais 10 anos e que faz parte de um grupo consolidado no mercado de educação no Ceará.

Os participantes da pesquisa foram os cinco professores que ministram as disciplinas de Economia, Economia Brasileira, Matemática, Contabilidade, Estatística, Matemática Financeira, Contabilidade e Custos, Gestão Financeira e Orçamentária. O número de alunos envolvidos durante os semestres variam entorno de 150 a 180 participantes o que representa aproximadamente 22 alunos por turmas. Para cada turma um representante que somava oito líderes que em conjunto com os professores direcionavam o trabalho e compuseram a amostra de um estudo longitudinal de 2010 a 2018.

A coleta dos dados ocorreu por meio da integração dos métodos de observação participante, relatos de experiências dos professores e dos alunos líderes de equipe e documentos institucionais analíticos, consolidando o uso da triangulação defendido por (Flick, 2013).

$\mathrm{Na}$ observação participante usou a técnica metodológica snowball também conhecida como snowball sampling (bola de neve) com fins a compreender o aprofundamento dos conhecimentos relacionados aos conceitos técnicos das disciplinas e a associação com os fundamentos da prática empreendedora implantada. O relato das experiências resgatou o memorial das informações guardadas no intelecto dos professores e alunos envolvidos no decorrer dos anos. Os documentos foram relatórios, projeto pedagógico, comunicação interna e fotos cedidas pela instituição.

Para entendimento da assimilação dos conhecimentos analisou-se as seguintes categorias, no tocante a educação empreendedora: rede de relacionamento, iniciativa, proatividade, inovação e liderança. Sobre as finanças comportamentais: hábitos comportamentos, tomada de decisão, conhecimentos financeiros.

Os dados foram analisados a partir de uma adaptação a luz da compreensão de (Bardin, 2009) que em sua técnica de análise de conteúdo defende que se deve utilizar de procedimentos sistemáticos e objetivos na descrição de mensagens.

\section{Análise e Discussão dos Resultados}

A metodologia implantada no Feirão do Imposto tem o propósito de estimular os estudantes na perspectiva de duas vertentes, a primeira está relacionada à educação para empreender por meio da formação de rede de relacionamento, proatividade, iniciativa e liderança. A segunda é sobre o horizonte das finanças comportamentais no ângulo de associar conhecimento, hábito e comportamento financeiro dos estudantes.

Os processos realizados pelos alunos sob a orientação dos professores iniciam com a identificação do produto que será exposto ou serviço ofertado e consequentemente a busca por uma empresa que disponibilize para que seja exposta em stands sob o planejamento e controle dos alunos que no decorrer do semestre são orientados com a formação de conhecimentos inerentes a economia, finanças, custos e outras informações que associadas de forma interdisciplinar vai construindo a base gestora e empreendedora desses futuros profissionais..

Essa ação faz parte do calendário acadêmico da instituição e ocorre anualmente, entretanto seu planejamento teórico inicia no primeiro semestre e sua implementação prática acontece no segundo semestre. A triangulação dos dados mostra uma associação de 
informações em relação à construção do conhecimento e a formação de comportamentos dos estudantes nas dimensões educação empreendedora e finanças comportamentais ao envolver os fatores psicológicos e sociológicos nas suas tomadas de decisões (Ricciardi \& Simon, 2000).

Inicialmente analisaram-se os conteúdos programáticos das disciplinas que dão suporte a prática onde foi possível identificar uma diversidade de elementos teóricos que sustentam a preparação e orientação dos estudantes quanto a conhecimentos que envolvem aspectos de cunho empreendedor com nivelamento em desenvolvimento econômico local, finanças tradicionais e comportamentais.

Partindo da constatação das informações na grade curricular, buscou-se saber dos alunos o entendimento dessa associação com o cotidiano e alguns relatos evidenciaram posições favoráveis e contraposições a formação de aspectos educativos e comportamentos orientados as finanças comportamentais. Como os destacados no relato dos alunos a seguir sobre a formação do grupo de trabalho e as decisões de escolhas do segmento: "Encontramos muitas dificuldades de integrar o grupo e ao mesmo tempo decidir o segmento de atuação, já que somos todos os dias bombardeados por muitas informações de várias disciplinas, além das experiências que a maioria tem do mercado advindas de estágio ou mesmo de carreira". Essa exposição nos revela uma congruência com o estudo de (Araújo, \& Davel,2018) sobre o dinamismo e a formação pessoal e profissional do empreendedor. Quando relacionado essa posição dos alunos com o discurso dos professores, observa-se uma congruência nos quesitos dificuldades de formação do grupo, estilo autocrático de liderança de alguns alunos, lacuna na adequação dos compromissos profissionais com as atividades acadêmicas, conforme a fala docente a seguir: " nossas dificuldades no processo de integrar teoria e prática faz parte de uma rotina que nos cabe desafios contínuos, já que muitos dos nossos alunos chegam com uma bagagem de experiência e exigências do mercado", ou seja, as barreiras não estão apenas na introdução de conteúdos associados a prática, mas no compromisso de levar o aluno a interdisciplinarizar esses conhecimentos com as distintas situações sistêmicas apresentadas no dia a dia pelo mercado. Esse relato condiz com as ideias de (Schaefer, \& Minello,2016) sobre a função do professor no estimulo a forma de pensar dos alunos. E congruente como pensamento de (Lima, Nassif, Lopes, \& Silva, 2014) sobre as distintas técnicas e estratégias pedagógicas para práticas de educação empreendedora e que muitas se estendem a aplicação em outras disciplinas que a leva a outra forma de educação, que não seja precisamente a formação empreendedora.

Em relação ao entendimento das atividades e as influencias em suas tomadas de decisões, observou-se que os alunos consideram interessante, mas acreditam que as decisões surgem de acordo com os acontecimentos."Somos exigidos demais, então pensar sem prever o futuro é melhor". "Às vezes é bom ter uma ideia do que vai acontecer, mas em algumas situações é melhor deixar chegar o momento para então a pessoa decidir o que vai fazer". Tal pensamento côngrua com a ideia de (Eatwell, Milgate \& Neumann,1987) sobre comportamento racional individual. Entretanto, o cenário de incertezas não permite muitas oportunidades de erros, mas de riscos calculados e moderados (Hisrich, \& Peters, 2004).

Quanto "ao cotidiano com os conhecimentos dos tributos embutidos nos produtos os relatos evidenciaram desconhecimentos." Sabe-se que o governo cobra impostos de tudo e que trabalhamos mais da metade do ano só para o governo, mas quando estamos sendo instruídos pelos professores para analisar o valor de cada tributo nos simples produtos que consumimos diariamente é que sentimos o quanto somos lesados pelo governo e que é 
necessário uma fiscalização mais cuidadosa da sociedade em relação às decisões governamentais". Essa ótica nos remonta as ideias de (Dolabela, \& Filion,2013) sobre a importância do professor estimular o aluno a aprender e a pensar fora da "caixinha", ou seja, dentro de um processo criativo e inovador, tanto na perspectiva da formação do empreendedor ou intraempreendedor.

Sobre as mudanças de hábitos e comportamentos financeiros, algumas posições dos alunos foram cruciais para entender que a integração da empresa com a universidade ainda tem suas barreiras, mas é um mecanismo de estimulo e motivação. "Achei super importante o que o empresário falou sobre pensar no futuro, não podemos gastar tudo que ganhamos". " $E$ que o bom administrador gerencia o presente com resultados futuros coerentes com as perspectivas ambientais internas e externas". "Acho muito valioso ouvir quem está enfrentando no dia a dia as dificuldades do mercado". "Às vezes nos livros tudo é muito acessível, mas a realidade é bem diferente”. Esses argumentos nos conduzem aos pensamentos de (Ritter,2002) sobre a psicologia cognitiva em relação aos processos mentais para a formação do comportamento humano. Ainda nesse limiar, o discurso do professor reforça as ideias expostas pelos alunos e se associa com a ideia de (Ritter,2002) ao discorrer que os alunos "tendem a demonstrar diante da teoria obrigatória, das experiências de colegas e professores uma necessidade de reafirmação daquelas informações por parte de alguém que esteja fora dos muros da universidade". "Buscamos compreender esses comportamentos como elementos agregadores na formação e no alinhamento das suas práticas com as exigidas pelo mercado".Essas afirmações dos professores e alunos são balizadas por distintos estudos sobre a sustentação da aprendizagem por meio da experiência (Krakauer, Santos, \& Almeida, 2017; Lima, Lopes, Nassif, \& Silva, 2015) e sobre métodos, técnicas e recursos pedagógicos para a Educação Empreendedora (Rocha, \& Freitas, 2014).

No questionamento sobre o processo criativo e as mudanças de comportamentos em relação as suas finanças, as argumentações foram que: "Enquanto estamos envolvidos no processo de identificar o produto, captar a empresa, entender a geração e o valor dos tributos, pensamos muito o quanto temos que mudar, porém, no dia seguinte são tantas informações e cobranças na faculdade e no trabalho, que acabamos não praticando da forma como foi ensinado". "Os professores reforçam sempre que as atividades práticas devem ser um adicional para a nota, mas a experiência deve ser levada para o mercado e para nossas mudanças economicas, sociais e ambientais". Consorciando essas falas com o estudo de (Schaefer, \& Minello, 2016) entende-se que dentre os distintos papeis da universidade está o de condução do seu corpo docente no limiar de uma ação que leve o aluno a entender os processos que formam a mudança e como lidar com as certezas e incertezas desse processo.

Ao que concerne o processo de reflexão sobre o papel da sociedade no acompanhamento do aumento dos tributos, os alunos demonstraram desconhecer a eficácia de ações continuas que geram resultados efetivos, conforme o discurso, "Sabemos que existem associações, ONG's, Leis e até muitas discussões de conteúdos obrigatórios em sala, mas no âmbito geral acredito que muitas ações são pontuais e que a sociedade não tem muita crença em suas próprias reivindicações". O papel de informar a instituição demonstra fazer na disseminação dessa prática e pelo discurso do professor estas informações são interdisciplinares. Para o professor essas informações "estão formalizadas na integração de vários conteúdos propagados nas disciplinas e ajustados em outras atividades práticas que o curso realiza ao longo da formação dos alunos". "Percebe-se a descrença dos alunos em relação a políticas efetivas de reestruturação de impostos nos níveis municipais, estaduais e 
federal tendo em vista a ineficiência de vários serviços públicos que deveriam receber esses recursos e ofertar um serviço com eficiência e eficácia para o cidadão".

Quanto à influência das atividades práticas no impacto das decisões financeiras dos alunos, embora estudo como de (Silva Filho, 2011) defenda que a economia como área interdisciplinar explique as decisões financeiras dos indivíduos e que os conteúdos analisados na grade curricular nas disciplinas de economia e economia brasileira tragam essas abordagens, o discurso dos alunos é que "as atividades práticas muitas vezes entram em dissonâncias com a experiência, o cotidiano profissional e que no tocante as questões financeiras o salário ou a bolsa de estágio já é comprometido com as despesas básicas, o que muitas vezes o sentimento de tantos impostos provoca revolta nas carências de oferta da qualidade dos serviços de saúde, educação e infraestrutura básica”.

Sobre a percepção dos alunos no tocante as decisões de identificar o produto ou serviço, a captação da empresa, os riscos, a exposição e a venda dos produtos ou oferta dos serviços, os argumentos são que "o primeiro passo é formar uma equipe unida, seguida do apoio de um empresário que acredite na ideia, um produto ou serviço barato e de fácil aceitação e no decorrer da organização cada colega assuma uma responsabilidade de acordo com as suas competências e habilidades". "E que os professores dão suporte, mas se o aluno não tiver interesse e compromisso só vai ganhar a nota". Esse conjunto de informações nos remonta os pensamentos de Kurniawan(2013) sobre educação empreendedora e o mundo dos negócios e tomada de decisões financeiras no processo de indivíduos, grupos e entidades (Ricciardi, \& Simon, 2000).

\section{Considerações Finais}

O projeto implantado mostra um avanço na promoção da educação empreendedora por meio do estimulo a comportamentos e características empreendedoras advindos do incentivo da instituição e da articulação da teoria com a prática o que torna um desafio continuo para os professores.

A simbiose desses dois construtos de fundamental relevância para os estudos da Administração mostra que por meio da educação empreendedora se pode extrair diferentes estados do indivíduo que permeiam desde o processo de formação de comportamentos para empreender a indícios de tomada de decisões sobre suas finanças comportamentais.

A consolidação do projeto ajuda a repensar a necessidade de ações efetivas da sociedade para cobrar dos poderes melhorias na oferta dos serviços e no controle do aumento dos impostos e consequentemente em suas aplicações.

Nessa ótica, os resultados desse estudo aglutinam-se em torno de um conjunto de dimensões experienciais dos alunos que mostram a existência de distintas aprendizagens, porém, mesmo com o reconhecimento do comprometimento dos altos índices de tributos na consolidação das suas finanças líquidas e nas deficiências da aplicação desses tributos embutidos em cada produto ou serviço consumido, os alunos não demonstraram que essas dimensões financeiras influenciem diretamente na formação dos seus comportamentos financeiros.

Por se tratar de uma pesquisa longitudinal, observa-se um avanço nos discursos dos alunos em relação aos aspectos de crescimento na formação empreendedora e tímidos comportamentos direcionados para as questões sociais e práticas que envolvem cotidiano do mercado. 
Outro achado salutar na pesquisa é que a instituição tem um projeto pedagógico que contempla uma educação voltada para procedimentos e questões criativas que envolvem a formação de um indivíduo capaz de pensar de forma sistêmica. No quesito corpo docente, observou-se uma integração e disponibilidade dos envolvidos diretamente com uma prática educativa interdisciplinar capaz de transcender muitas das exigências do mercado como o dinamismo, capacidade de trabalhar em equipe e um olhar coerente com as questões de caráter econômico e social.

Os resultados apontaram uma disposição dos estudantes em relação aos aspectos de formação para empreender, da necessidade de implantação de ações efetivas para cobrar dos poderes executivos e legislativos melhorias na oferta dos serviços públicos, no controle do aumento dos impostos e na transparência da aplicação dos recursos.Entretanto, não apresentaram conhecimentos inerentes a modificações de comportamentos relacionados ao cotidiano financeiro.

Para estudos futuros, sugere-se uma análise comparativa com os alunos que participam da prática com os egressos que participaram. Outra proposta é verificar a existência de mudanças de comportamentos na rotatividade de participação dos alunos e as orientações dos professores. Um estudo quantitativo e qualitativo com a participação dos alunos envolvidos e os propensos a participarem em eventos futuros.

Em relação às limitações encontradas no decorrer da pesquisa, pode-se afirmar que uns dos maiores entravem está no condensamento de informações no processo de triangulação dos dados.

\section{Referências}

Araujo, G. F., \& Davel, E. (2018). Educação Empreendedora, Experiência e John Dewey. Revista Pensamento Contemporâneo em Administração, 12(4), 1-16.

Banco Mundial (2014). Financial Education Programs and Strategies: Approaches and Available Resources. Washington: World Bank Group.

Brito, N. D. (2016). Sucesso do microempreendedor individual no Brasil. (Dissertação) Mestrado de Administração da Faculdade de Economia, Administração e Contabilidade da Universidade de São Paulo. São Paulo, São Paulo, Brasil.

Chemmanur, T. J., \& Fulghieri, P. (2014).Entrepreneurial finance and innovation: An introduction and agenda for future research. Review of Financial Studies, 27(1), pp. 1-19.

Cardoso, A. M. (2017). Educação empreendedora: métodos alternativos de ensino e aprendizagem para formação do empreendedor. Campo Limpo Paulista, SP: FACCAMP.

Delors, J. (2012). Educação: um tesouro a descobrir. São Paulo: Cortez; Brasília, DF: UNESCO.

Envick, B. R. (2001). Entrepreneurship programs versus traditional business programs: understanding different needs. Journal of Entrepreneurship Education, 7(2), pp. 2-10.

Ferreira, J. K. F. S., Silva, R. F. M., \& Guilherme, H. F. (2003). Um panorama evolutivo das finanças e a aplicação das finanças Comportamentais na análise de tomada de decisão dos Investidores no mercado de capitais. In: III Seminário Universidade Federal de Pernambuco de Ciências Contábeis, Recife.

Filion, L. J. (1999). Empreendedorismo: empreendedores e proprietários-gerentes de pequenos negócios. Revista de Administração, 34(2), 05-28. 
Gerba, D. T. (2012). Impact of entrepreneurship education on entrepreneurial intentions of business and engineering students in Ethiopia.African Journal of Economic and Management Studies, vol. 3 No. 2.pp. 258-277.

Glacking, C., Byrd, K., \& Phelan, S. (2016). Contextual Considerations in Entrepreneurial Finance Education: A Systematical Analysis of U.S. Undergraduated Courses. Academy of Entrepreneurship Journal, 22(2), pp. 13-28.

Halfeld, M., \& Torres, F. F. L. (2001) Finanças Comportamentais: aplicações no contexto brasileiro. Revista de Administração de Empresas, v. 41, n. 2, p. 64-71.

Nurseto, T. (2010). Pendidikan Berbasis Entrepreneur. Journal Pendidikan Akuntansi Indonesia, vol. 8, n. 2, p. 25-41.

Khan, E. A., Mohammad, S., \& Alam Nur, M. (2010). Factors Affecting the Growth of Entrepreneurship in Small-Scale Business. Business Review, 5(1), pp. 33-37.

Krakauer, P. V. C. (2014). Ensino de empreendedorismo: estudo exploratório sobre a aplicação da teoria experiencial. (Tese (Doutorado). Faculdade de Economia, Administração e Contabilidade, Universidade de São Paulo - USP. São Paulo, São Paulo, Brasil.

Krakauer, P. V. C. (2011). A utilização das informações do ambiente no processo de decisão estratégica: estudo com empresários brasileiros e americanos de pequenas e médias empresas. 137p. Dissertação (Mestrado em Administração) - Faculdade de economia, administração e contabilidade, Universidade de São Paulo, São Paulo.

Kurniawan, R. (2013). Pengaruh Penerapan Model Pembelajaran Teaching Factory 6Langkah (TF-6M) dan Prestasi Belajar kewirausahaan Terhadap MinatWirausaha. Journal Pendidikan Teknologi Kejuruan, vol. 10, n. 1, pp. 57-66.

Libâneo, J. C.(2013). Didática. São Paulo: Cortez, 2013.

Lima, E., Lopes, R. M. A., Nassif, V., \& Silva, D. (2011). Intenções e Atividades Empreendedoras dos Estudantes Universitários - Relatório do Estudo GUESSS Brasil 2011. Grupo APOE - Grupo de Estudo sobre Administração de Pequenas Organizações e Empreendedorismo, PMDA-UNINOVE. Caderno de pesquisa, n. 2011-01. São Paulo: UNINOVE.

Lima, E., Lopes, R. M. A., Nassif, V. M. J., \& Silva, D. (2015). Opportunities to Improve Entrepreneurship Education: Contributions Considering Brazilian Challenges. Journal of Small Business Management, v. 53, p. 1033-1051.

Martinelli, L. A. S., \& Flemming, E. S. (2010). O Comportamento Empreendedor: a Influência das Características Emocionais na Motivação dos Indivíduos para a Ação Empreendedora. In: XXXIV Encontro da ANPAD.

Matias, M. A., Colares, A. C. V., Rocha, P. M., \& Carvalho Junior, L. E. (2013). O ensino de empreendedorismo nos cursos de graduação em ciências contábeis. Revista Catarinense da Ciência Contábil, v. 12, n. 35, p. 63-78.

Minayo, M. C. S. (2007). O desafio do conhecimento: pesquisa qualitativa em saúde. 8 ed. São Paulo: Hucitec.

Mcclelland, D. C., \& Johnson, E. W. (1984). Learning to Achieve. Glenview, Illinois: Scotti. Foresman \& Co.

Mwasalwiba, E. (2010). Entrepreneurship education: A review of its objectives, teaching methods, and impact indicators. Education + Training, 52(1), pp. 20-47.

Nassif, V. M. J., Amaral, D. J., \& Prando, R. A. (2012). A universidade desenvolve competências empreendedoras? Um mapeamento das práticas de ensino numa universidade brasileira. Administração: Ensino e Pesquisa, Rio de Janeiro, v. 13, n. 3, p. 597-628. 
Neck, H. M., Neck, C. P., \& Murray, E. L. (2018). Entrepreneurship: the practice and mindset. London: SAGE.

Hjorth, D. (2011). On provocation, education and entrepreneurship. Entrepreneurship \& Regional Development, 23(1-2), 49-63.

Pompian, M. M. (2006). Behavioural finance and wealth management: Building optimal portfolios that account for investor biases. New Youk: John Wiley \& Sons.

Ritter, J. R. (2002).Behavioural Finance. Science Direct-Pacific Basim Finance Journal, 2-12. Ross, S., Westerfield, R., Jaffe, J., \& Jordan, B. S. (2008).Modern Financial Management. New York: McGraw Hill.

Rogers, S. (2011). Finanças e estratégias de negócios para empreendedores. Porto Alegre, Rio Grande do Sul: Artmed.

Rogers, P. (2007). Finanças Comportamentais no Brasil: Um Estudo Comparativo. In: $7^{\circ}$ Congresso USP de Contabilidade e Controladoria. São Paulo. Anais.

Schaefer, R. Minello, I. F. (2016). Educação Empreendedora: Premissas, Objetivos e Metodologias. Revista Pensamento Contemporânea de Administração, v.10, n.3, Jul-Set., pp. 60-81.

Solomon, G. T., Duffy, S. E., \& Tarabishy, A. (2002). The State of Entrepreneurship Education in the United States: A Nationwide Survey and Analysys. International Journal of Entrepreneurship Education, 1(1): 1-22.

Subrahmanyam, A. (2007). Behavioural finance: A review and synthesis. European Financial Management, 14(1), 1229.

Tseng, K. C. (2006).Behavioural finance, bounded rationality, neuro-finance, and traditional finance. Investment Management and Financial Innovations, 3(4), 7, p. 18.

Tversky, A., \& Kahneman, D. (1986). Rational choice and the framing of decisions. Journal of Business, v. 59, p. 251-278.

UNCTAD Secretariat (2011). "Entrepreneurship Education, Innovation and CapacityBuilding in Developing Countries," United Nations Conference on Trade and Development (UNCTAD), Geneva. http://unctad.org/en/docs/ciimem1d9_en.pdf. Acesso em mai 19, 2019. Unger, J. M., Rauch, A., Frese, M., \& Rosenbusch, N. (2011). Human capital and entrepreneurial success: A meta-analytical review. Journal of Business Venturing, 26(3), pp. 341-358.

Vanevenhoven, J. (2013). Advances and Challenges in Entrepreneurship Education. Journal of Small Business Management.

Verdinelli, M. A., Lizote, S. A., Nascimento, S., \& Ramezanali, M. (2015).Relationship between personal finance and characteristics of Brazilian accounting university students. In: Proceeding of Crongress of European Academy of Management EURAM.

Yamamoto, R. G. (2018) Educação Empreendedora: uma Proposição de Conteúdos de Finanças em Cursos de Graduação. (Dissertação de Mestrado). Mestrado Profissional em Administração. Fundação Escola de Comércio Álvares Penteado - FECAP. São Paulo, São Pualo, Brasil.

Yoshinaga, C., Oliveira, R., Silveira, A., \& Barros, L. (2008). An introduction to behavioral finance . REGE Revista De Gestão, 15(3), 25-35.

Welsh, D. B., Tullar, W. L., \& Nemati, H. (2016). Entrepreneurship education: Process, methodor both? Journal of Innovation and Knowledge, 1(3), pp. 125-132.

William, B. G., Casey, J. F., \& John, C. A. (2012). Financing the emerging firm. Small Business Economics, 39(3), pp. 745-761. 